\title{
A.JOTE
}

African Journal of Teacher Education

ISSN 1916-7822. A Journal of Spread Corporation

Volume 10. No. 12021 Pages 21-37

\section{Inclusive Physical Education During the University Preparation Programme in Ghana: Bridging the Gap Between Theory and Practice.}

\author{
${ }^{1}$ Regina Akuffo Darko, ${ }^{2}$ Jane Mwangi \& ${ }^{2}$ Lucy Joy Wachira \\ ${ }^{1}$ Department of Health, Physical Education, Recreation and Sports \\ University of Education, Winneba, Ghana \\ ${ }^{2}$ Department of Physical Education, Exercise and Sports Science
}

Kenyatta University, Kenya

\begin{abstract}
Hands-on experience plays a key role in every teacher education programme as it helps the prospective teacher to experience a real world of teaching rather than in abstract. One of the most difficult aspects of inclusive teacher education programmes is capacitating pre-service teachers to practice inclusion in the classroom in real live conditions. This study aimed at evaluating student-teachers' hands-on experiences in inclusive practical PE lessons during their university preparation programme using sequential mixed-method design. 152 PE studentteachers' in level 300 from the two universities who train PE teachers in Ghana were purposively sampled for this study. Quantitative data was collected using questionnaires while qualitative data was collected through focus group discussion with 20 of the same participants. Quantitative data were analysed using means and standard deviation and presented in tables. Inferential statistics of independent t-test was used to ascertain the mean difference between studentteachers' hands-on experiences. Qualitative data were transcribed verbatim with trustworthiness assured through peer debriefing and member checking. Both quantitative and qualitative results showed that the university preparation programme has no practical component for inclusion in PE. Student-teachers' hands-on teaching experience in inclusive practical PE was found to be inadequate. However, a significant difference ( $($ (-4.020) at df(32.9), $p<.005)$ was found between the two institutions. The study concludes that the preparation programme in the universities does not give student-teachers' adequate inclusive practical exposure. To make inclusion experience more viable to student-teachers', it is recommended that inclusive experiences should be
\end{abstract}

*Corresponding author email: myaniger28@gmail.com 
incorporated into student-teachers' on-campus teaching practice and all practical courses to help bridge the gap between theory and practice.

Keywords: hands-on experience, practical, physical education, inclusion, students with disabilities

\section{Introduction}

Physical education (PE) programme focuses on the educational value of physical activity (PA) oriented towards the multilateral and harmonious development of all learners in diverse class settings. PE encompasses education that emanates from knowledge resulting from experimentation in practical activities that develop skills in the cognitive, affective and psychomotor domains (Pańczyk et al, 2008).

Practical PE demands a more physically oriented learning environment, separate from classroom-based subjects. Nonetheless, one sure way to develop the requisite skills which is deemed irreplaceable, that enables an increase in awareness of movements for an individual is through experience of the practice of bodily activities and human movement (Secretaria da Educação Básica, 2017). This is what PE practical lessons offers to all learners.

From a practical point of view, PE involves a deliberate selection of certain tasks of teaching and educational purposes. These tasks are further subordinated to methodical units, taking into account the principles of construction of physical activities and ensuring the optimum conditions for personal development, physical fitness and motor exercises (Pańczyk et al 2008). For the PE teacher to achieve the objective and goals set for a practical lesson, it calls for a focus on the art and science of teaching which involve vital ways of critically scrutinising and designing transformative and genuinely pluralistic PE practices.

However, in order for a competent PE teacher to do this, there is the need to reclaim the art and science of teaching in PE, which is about being educative and making judgements about what to bring to the practical lesson setting especially where there is diversity of learners (Quennerstedt, 2019). These unique factors of practical PE as a general education course call for teacher training programmes that equally meet the demands that the practical aspect of the subject requires especially when considering inclusion in practical lessons. It is evidently clear, therefore, 
to place importance of focusing on contextual concept of students with disabilities (SWD) in an inclusive practical PE compared to other classroom-based subjects (Secretaria da Educação Básica, 2017), hence, the need for this study.

The introduction of inclusive education (IE) policy in Ghana is currently challenging school organisations in making the general curriculum accessible to all learners (Nketsia et al., 2016). Researchers have highlighted the grandness of a hands-on approach when planning to teach students with disabilities as it permits student-teachers to employ theoretical knowledge in an authentic field-based experience (Di Nardo et al., 2014; Pederson, et, al, 2014). Moreover, according to Pederson et al, (2014), more practicum experiences are reflections of what preservice PE teachers will experience in their careers and it is therefore needed during their training. However, in Ghana, existing patterns of teacher preparation programme follow the traditional teacher education approach with emphasis on teaching a regular class with less focus on inclusion (Deku \& Vanderpuye, 2017).

One of the most difficult aspects of inclusive teacher education programmes is the ability of pre-service teachers to practice inclusion in real life lessons. This has been highlighted well in the global UNICEF report (2012). Many respondents who participated in the UNICEF project felt that theoretical knowledge contained in teacher education programmes does not always translate into classroom practice. The report failed to identify the reasons for ongoing gaps between theory and practice aspects of inclusive education. There are various reasons why theoretical information covered in teacher education programmes fail to make an impact in teaching practices of pre-service teachers. This is because universities and schools are two dissimilar worlds. The information covered in teacher education programmes often is too distant from the realities of the classrooms (Sharma \& Loreman, 2014). More so, Goodwin and RossowKimball (2012) pointed out that successful experiences of PE teachers with students with disabilities can positively reinforce how teachers perceive their competence to adequately deal with the various situations during class. Hence, Block et al. (2013) described the need to evaluate inclusive practical experiences of pre-service PE teachers.

Furthermore, a study conducted by the Organisation for Economic Co-operation and Development - OECD (Schleicher, 2016) found that a large number of student-teachers' biggest challenge in all participating OECD countries was their lack of preparedness and unwillingness 
to teach students with disabilities. While some universities covered theoretical concepts about disabilities and inclusion, none of the universities had any practical component focused on the practice of inclusion (Sharma, 2018). Thus, one aspect of the teacher training programme that needs to be given significant attention relates to addressing gaps between theory and practice of inclusion.

Nevertheless, there is paucity with regards to information about the adequacy of the preparatory programme in terms of hands-on experiences at the university level for including students with disabilities in practical lessons in Ghana. Student-teachers' subject-matter content knowledge and pedagogical content knowledge are supposed to be merged by the university student-teacher preparation programme (Ntim, 2017) through hands-on experiences. Any failure of the university preparation programme to expose student-teachers' to practical experiences will questioned the validity of the programme. As a result, the adequacy of PE student-teachers' ability and competence to include students with disabilities in their regular PE lessons will be insignificant leading to potential decrease in quality teaching and learning of practical PE in an inclusive setting. Most studies conducted globally that has been reviewed perceived a probable lack of experience in the teacher-preparation programmes for inclusion but that of Ghana in the area of PE has not been evaluated. Hence, this study aimed at evaluating student-teachers' handson experiences in inclusive practical PE lessons during their university preparation programme in Ghana. This study was based on Kolb's (1984) experiential learning theory. The theory presents an approach that specifies how a course or a programme may be imparted to maximise a student's learning process. It proposes that learning is cyclical, comprising four phases, often referred to as knowing or feeling, observing or reflecting, thinking and doing.

\section{Methods}

The sequential mixed-method design was used for this study. With this design, two approaches were used to collect data from the student-teachers' first, using a questionnaire followed by a focus group discussion (FGD). Participants were third year PE student-teachers' of Department of Health, Physical Education and Recreation, in the University of Cape Coast (UCC) and the Department of Health, Physical Education, Recreation and Sports in the University of Education, Winneba (UEW). These student-teachers' were purposively selected for this study because they had completed all their 3 years on-campus programme content taught courses and were about to 
go out for internship. Student-teachers' who reported to have taken additional refresher courses in special needs education were excluded from the study. Ethical clearance was sought from the Institutional Review Board of UCC and the departmental heads of the two institutions before data was collected. Participants were assured of confidentiality and freedom to withdraw from the study at any time without requital.

The sample size for the quantitative data was 152 while that for the qualitative data was 20 of the same participants who were proportionally selected. Data were collected first using a researcher designed 5-point Likert scale type questionnaire made up of 8 items which was content and face validated by specialists in the area. The Qualitative data were collected after the all the quantitative data has been collected and analysed using FGD. This helped to augment the data collected with the questionnaire. The FGD took place in MPhil lecture halls in the two institutions on a scheduled date and time. It was first carried out in UCC and then in UEW. Audio recordings were played back to the participants to ensure confirmability. Quantitative data were cleaned and then coded using IBM SPSS version 25. Data were scored by summative index of all the 8 items with average score of 3 . Below 3 means disagreement and above 3 means agreement with the statements. The quantitative data were analyzed using descriptive statistics of mean and standard deviation and presented in tables. Inferential statistic of t-test was used to ascertain the mean difference between the hands-on experience of the student-teachers' from the two institutions with alpha level of 0.05 for two tail. Qualitative data were transcribed verbatim based on the research question. Trustworthiness was assured through peer debriefing and member checking.

\section{Results}

\section{Student-Teachers' Hands-on Experience in Inclusive Practical PE Teaching}

The responses from the student-teachers' indicated that the majority of them disagreed with all the items under practical experience with students with disabilities in an inclusive setting. From Table 1, all the items recorded a mean below 2.88 out of the average mean of 3.0. This implied that, the preparatory programme in the University has not exposed student-teachers' to hands-on experiences in inclusion and in an inclusive setting. Student-teachers' have not had the opportunity to observe an inclusive PE lesson $(\mathrm{M}=2.64, \mathrm{SD}=1.26)$ neither have they had the opportunity to interact with an inclusive class setting $(\mathrm{M}=2.76, \mathrm{SD}=1.24)$. This implies that 
though student-teachers' are being trained yet there is paucity in their exposure to inclusive practical PE.

Table 1: Student-Teachers' Responses to PE Practical Experiences with Students with Disabilities in an Inclusive Setting

\begin{tabular}{llll}
\hline Items & N & Mean & SD
\end{tabular}

1. I have had the opportunity to observe students with and without disabilities PE practical lessons in an inclusive setting

$152 \quad 2.6447 \quad 1.26286$
during my preparation programme.

2. I have had an opportunity to interact with students with and without disabilities in an inclusive PE practical lesson during my preparation programme.

3. I have had the opportunity to pair students without disabilities with SWDs to learn/practice a skill effectively.

4. I have had the opportunity to supervise students with and without disabilities while they practice a skill in an inclusive practical PE lesson.

5. I have had the opportunity to adequately demonstrate/describe skills to students with varying disabilities in an inclusive

PE practical setting.

6. I had the opportunity to practically assess students with and without disabilities in 152 an inclusive practical PE lesson. 
7. I have had the opportunity to practice how to present skill in parts to allow students with and without disabilities to $152 \quad 2.6645 \quad 1.16769$ learn efficiently.

8. I have had the opportunity to practice how to vary the pace of lesson delivery to help students with and without $152 \quad 2.6382 \quad 1.16545$ disabilities learn skills.

\section{Abbreviation: N - Total Number of Participants, SD - Standard Deviation}

An independent sample t-test assuming unequal variance was used to test the null hypothesis which stated that there is no significant difference between the hands-on experiences of studentteachers' in the two universities. Table 2 shows that there was a significant difference between the hands-on experiences of the student-teachers' in the two universities. The result indicated that UEW student-teachers' $(M=22.36, \mathrm{SD}=6.57)$ showed more hands-on experiences than their colleagues from UCC $(\mathrm{M}=16.28, \mathrm{SD}=6.97)$. From Table 2, $\mathrm{t}(-4.020)$ at $\mathrm{df}(32.9), \mathrm{p}<.005$ was significant with Hedges' $g$ of 0.90 . The null hypothesis was therefore rejected. The result is presented in Table 2.

Table 2: T-Test Results Showing Difference between Student-Teachers' Hands-OnExperience for Inclusive Practical PE in the Two Universities

95\% Confidence

Interval of the

\begin{tabular}{lccccccc} 
& & & Sig. (2- & Mean & Std. Error & \multicolumn{2}{c}{ Difference } \\
& $\mathrm{t}$ & $\mathrm{df}$ & tailed) & Difference & Difference & Lower & Upper \\
\hline $\begin{array}{l}\text { Equal variances } \\
\text { assumed }\end{array}$ & -4.187 & 150 & .000 & -6.08220 & 1.45272 & -8.95265 & -3.21176 \\
$\begin{array}{l}\text { Equal variances } \\
\text { not assumed }\end{array}$ & -4.020 & 32.921 & .000 & -6.08220 & 1.51280 & -9.16030 & -3.00411 \\
\hline
\end{tabular}

Abbreviation: $t$-t-test value, $d f$ - degree of freedom, Significant $* * 0<0.05 d f=32.9$ 
To describe and also to get in-depth information about student-teachers' hands-on experiences in inclusive practical PE lessons during their university preparation programme, a focus group discussion aspect of the study was carried out. Student-teachers' from UEW seem to have visited segregated schools and reported that they have observed students with disabilities in their practical lessons but did not have the opportunity to teach them as they would have wished, for personal experience. Some views shared by some of the student-teachers' were as follows:

\section{One male participant said:}

"When we went to visit classified people at disabilities centres, we took part in their PA programmes. This gave us a prior knowledge about how they conduct their PE lessons, so that is why I am saying I have hands-on exposure in terms of practicals” (FGD Participant, UEW 2019).

\section{On the contrary one female student was of the view that:}

“. . . there is the saying that we learn more by doing so since I have not experienced and also not had the exposure, I will say I don't have any handson experience" (FGD Participant, UEW 2019).

\section{Another male student reported that:}

"We all know that theory is different from practice. I have gotten the theoretical knowledge but for practical experience, I will say a big 'No'” (FGD Participant, UEW 2019).

All participants from UCC responded 'No' by shaking their head to their hands-on experience. Some went on to further suggest what they needed to do since they have not had any practical exposure and gave their views as follows:

\section{A male participant from UCC reported that:}

"I have no exposure; I need to start reading about disability and how to involve them in our practical lessons. And also, most effectively, we should look at Europe and the outside world; most of their activities go with equipment and you have to know how to use that equipment and how to improvise them. I have to start looking at ways to involve them. Let's say if am going to teach volleyball, how do I improvise to suit someone who is able to use the hand but 
cannot walk. How will I involve such a person in my volleyball class? I have to start reading to have basic knowledge about handling such individuals" (FGD Participant, UCC 2019).

\section{Another male participant said:}

"There is more we need to do; more we need to know and more we need to learn. So, what will be the best for us is to go out there and read more about SWDs, how to handle them and involve them in activities and also how to involve them with people without disabilities so that in all, everybody will benefit" (FGD Participant, UCC 2019).

\section{Another participant said:}

"I think we should start writing proposals and articles on those issues to push an agenda if they can as well include us or include the inclusive schools to our programme. With this, we can have part of our off-campus teaching practice in inclusive and special schools. Even if it's just for a week or two, at least we will learn something so that if we go out there, we will be fully-baked. Now we are half-baked; we are just waiting for issues to come up" (FGD Male Participant, UCC 2019).

\section{A female participant said:}

"I also think that we need to learn more, and also find out how we can handle SWDs when we meet them in the schools. I can actually see we have a lot to do in terms of practicals in inclusive schools. From today, I will learn more and also visit some of their schools to know how to handle these people". (FGD Participant, UCC 2019).

\section{Another student suggested that:}

“... We can just integrate practicals into what we are already learning so that any practical lesson they will just spend about thirty minutes and teach us how we can adjust when we kind of have such a student in our class. So, a student 
may simulate that situation and we see how best we can help the student go through it” (FGD Male Participant UCC, 2019).

\section{Discussions}

An innovative trend in teacher education programmes that prepare teachers to teach in inclusive settings has been identified as an infusion of inclusive knowledge and practice into all content areas and subjects of the initial teacher-education curriculum (Nash \& Norwich, 2010). Researchers have highlighted the grandness of a hands-on approach when planning to teach students with disabilities as it enables students to apply their theoretical knowledge in an authentic field-based experience (Di Nardo et al., 2014; Pederson et al., 2014). Research has shown that student-teachers' in PE may not experience interaction with students with disabilities or teach these students until they have begun teaching within schools (Travers et al., 2010). These assertions align with the findings of the current study whereby all items under hands-on experiences recorded low means (i.e. below 3.0). Though all items recorded low means, a significant difference was found to exist between the student-teachers' from the two institutions when data was subjected to further inferential statistics of independent t-test. Perhaps a reason for this significant difference might be due to programme differentiation.

The focus group discussion results on student-teachers' practical experience for the inclusion of students with disabilities in practical PE revealed that student-teachers' from UEW had the opportunity to observe PE lessons of students with disabilities in their segregated environment once during their (student-teachers') Adapted Physical Education course. Participants from UCC said they have neither had any practical experience with students with disabilities nor thought of students with disabilities being part of their PE class one day. This is clear evidence that the two universities in Ghana need to restructure their courses to make room for inclusive practical experiences in an inclusive setting for student-teachers' before they move to the real world (school setting). In the application of experiential learning theory, contextual learning approaches like experiential learning (Kolb, 2015), and situated learning were found to help educators to nurture integrated learners who are as sensitive to context as they are to abstract concepts.

The current finding agrees with that of Sprecht et al. (2015) who revealed that positive attitudes and self-efficacy of teachers towards inclusive education is promoted by the 
restructuring of their school-based experience. This enable teachers to have direct and systematic interaction with students with disabilities and teaching in an inclusive setting. Also, a study by Gaintza and Castro (2020) suggested that the type of activity proposed and the working methodology in PE sessions can be crucial in creating suitable experiences for student-teachers'.

The focus group results also showed the majority of the student-teachers' expressing the opinion that there should be an opportunity for them to have practical experience with students with disabilities. They were of the view that theory is different from practice, therefore when the theories are taught in the classroom to them, they should also be given the opportunity to practice what has been taught in a real-world situation. With this, they can better understand the concept and also better put the theoretical concept into meaningful practice. Furthermore, they expressed that having practical exposure will help them to get the opportunity to observe how teachers use specific teaching techniques and strategies in inclusive settings. In support of this current finding, Haegele et al. (2018), analysed 90 Brazilian PE teachers and certified that participants' attitudes were considerably impacted by their experiences during the lessons. This implies that though student-teachers' have a positive intention to include students with disabilities, a further practical experience will build their confidence and attitude to carry out inclusive practical lessons successfully, all things being equal.

A similar finding to this current study is that of Sharma (2018) who stated that, although theoretical concepts about disabilities and inclusion were taught in some universities, none had any practical component focused on the practice of inclusion. In support of this current study finding, Swanson et al. (2013) also found a disconnection between the knowledge of inclusion as presented through the university coursework and the students' real-world field-experience.

More optimistically, Allen and Wright (2014) studied the integration of theory and practices in pre-service teacher education practicum placements and reported that participants overwhelmingly backed the concept of linking university coursework to the practicum. This, they reported, would serve to bridge the gap between the university and the school, as well as between theory and practice. This assertion by Allen and Wright (2014) correlates with most of the views shared by student-teachers' during the focus group discussion in this current study. Against this backdrop, it can be said that student-teachers' need teaching practice in general classes that include learners with diverse disabilities in PE. Teachers and lecturers who are qualified and 
experienced in inclusive PE should mentor them in such teaching practice so that they can be equipped with both the relevant theory and practice (Majoko, 2019).

To infuse some hands-on experiences in the preparation programme, other studentteachers' in the focus group discussion suggested that they should have simulations of situations where a person with disability is present in a practical lesson. They also suggested introducing a practical session with students with disabilities during On-Campus Teaching Practice (OCTP). These suggestions are in agreement with the observations of Block et al. (2017) who reviewed and summarized a number of teacher preparation processes and made similar recommendations as: providing simulations of disability conditions while attempting to perform various physical activities, infusing disability-related contents across core curriculum studies as well as participating in on-campus and off-campus practicum sessions. What this suggests is that for inclusive PE to be effective and up to expectations, it behooves on the two departments to factor in simulations during practical sessions, practical experiences as part of the OCTP course, and also factor in practical experience in inclusive settings.

\section{Findings and Conclusion}

Student-teachers' hands-on teaching experience in inclusive practical PE in these two Ghanaian university teacher education preparation programme was found be inadequate. Nevertheless, a significant difference was found to exist between the practical experience of student-teachers' from University of Cape Coast and University of Education, Winneba even though they both indicated that their practical exposure was inadequate. The study revealed that university of education student-teachers' exposure to practical physical education for students with disabilities was in segregated schools and not in inclusive settings. Student-teachers' were of the view that practical experience in segregated schools was not enough for their hands-on experiences for inclusion in practical PE. It was also found that student-teachers' were prepared to go an extra mile by visiting inclusive schools to learn how to handle students with disabilities in practical PE lessons. With this, student-teachers' advocated that inclusive schools should be added to their practicum schools so that they can have exposure in order to be fully capacitated.

The study draws the conclusion that the preparation programme in the universities do not give student-teachers' adequate inclusive practical exposure and, therefore, should be restructured to meet the demands of inclusion in Ghanaian schools. The university preparation programmes 
do not have a practical component for inclusion in PE. Practical experience tends to build confidence and competence in student-teachers' to be able to teach students with disabilities in an inclusive practical PE lesson. A blend of theory and practical experience as well as varied methodology would help student-teachers' to bridge the gap between theory and practice for inclusion in PE.

\section{$\underline{\text { Recommendation }}$}

It is recommended that University of Education, Winneba should re-examine the curriculum content of student-teachers' Adapted PE course and incorporate the practicum aspect into it. Also, the two universities should bridge the programme gaps between theory and practice by giving student-teachers hands-on experiences in inclusive practical PE during their training programme in the universities.

\section{Acknowledgments}

The researchers thank all student-teachers from the two institutions who agreed to participate in this study. Further thanks go to all research assistants who helped in making the data collection process a success.

\section{Declaration of Conflict of Interests}

The authors declare no potential conflict of interest.

\section{Funding}

The authors received no financial support for this research or publication of this article.

\section{Ethical approval}

Ethical clearance for this study was sought from the institutional review board of UCC

(ID number: UCCIRB/EXT/2019/16). Permission was also obtained from the departmental heads of the two institutions in Ghana. 


\section{Informed consent}

Student-teachers' consent was sought for prior to data collection and they were assured of confidentiality as well as withdrawing from the study without any reprisal.

\section{Authors contributions}

Regina Akuffo Darko wrote the introduction of this manuscript and conducted the field work from which was obtained the data for the analysis. Dr. Jane Mwangi wrote the discussion for this manuscript and Dr. Lucy Joy Wachira wrote the methodology for this manuscript. All authors reviewed the final manuscript.

\section{REFERENCES}

Allen, J. M., \& Wright, S. E. (2014). Integrating theory and practice in the pre-service teacher education practicum. Teachers and Teaching, 20(2), 136-151.

\section{DOI: $\underline{10.1080 / 13540602.2013 .848568}$}

Behrstock-Sherratt, E., Bassett, K., Olson, D., \& Jacques, C. (2014). From good to great: Exemplary teachers share perspectives on increasing teacher effectiveness across the career continuum

http://www.gtlcenter.org/products-resources/study-teacher-perspectives-factorsinfluencing-effectiveness

Block, M. E., Hutzler, Y., Barak, S., \& Klavina, A. (2013). Creation and validation of the self-efficacy instrument for physical education teacher education majors toward inclusion. Adapted Physical Activity Quarterly, 30(2), 184-205.

DOI: $10.1123 /$ apaq.30.2.184

Block, M., Grenier, M \& Hutzler, Y (2017). Strategies to maximize social participation and inclusive of students with disabilities in physical education. In: Morin AJS, Maïano C, 
Tracey D, Craven RG, editors. Inclusive Physical Activities: International Perspectives. Charlotte, NC: Information Age Publishing;. pp. 109-132

Deku, P. \& Vanderpuye, I. (2017). Perspective of teachers regarding inclusive education in Ghana. International Journal of Whole Schooling. 13(3), 39-54.

Di Nardo, M., Kudlacek, M., Tafuri, D., \& Sklenarikova, J (2014). Attitudes of pre-service physical educators towards individuals with individuals with disabilities at university Parthenope of Napoli. Acta Gymnica 44(4), 211-221. doi:10.5507/ag.2014.022

Fitzgerald, H (2012). Drawing on disabled students experiences of physical education and stakeholders responses. Sports education and society 17(4):443-462

https://doi.org/10.1080/13573322.2011.609290

Gaintza, Z, \& Castro, V. (2020). Physical education sessions in secondary school: Attitudes towards the inclusion of students with disabilities Journal of Physical Education and Sport 20 (1), Art 28 pp. 214 - 221, 2020 DOI:10.7752/jpes.2020.01028

Goodwin, D. L., \& Rossow-Kimball, B. (2012). Thinking ethically about professional practice in adapted physical activity. Adapted Physical Activity Quarterly, 29(4), 295-309.

DOI: 10.1123/apaq.29.4.295

Haegele, J. A., Hodge, S., Gutierres Filho, P. J. B., \& Rezende, A. L. G. de. (2018). Brazilian physical education teachers' attitudes toward inclusion before and after participation in a professional development workshop. European Physical Education Review, 24(1), 21-38. DOI: $10.1177 / 1356336$ X16662898

Jin, Y., Yun, J \& Wegis H. (2013). Changing physical education teacher education curriculum to promote inclusion. Quest, 65:372-383. National Association for Kinesiology in Higher Education (NAKHE). ISSN: 0033-6297 print / 1543-2750.

DOI: $10.1080 / 00336297.2013 .791869$

Kolb, D. (1984). Experiential learning: Experience as the source of learning and development. Englewood Cliffs, NJ: Prentice-Hall, Inc.

Kolb, D. A. (2015). Experiential learning: Experience as the source of learning and development. Upper Saddle River, NJ: Pearson Education 
Majoko, T (2019). Inclusion of children with disabilities in physical education in Zimbabwean primary schools. SAGE Open. journals.sagepub.com/home/sgo

DOI: $10.1177 / 2158244018820387$

Nash, T., \& Norwich, B. (2010). The initial training of teachers to teach children with special educational needs: A national survey of English postgraduate certificate of education programmes. Teaching and Teacher Education, 26, 1471-1480. DOI:10.1016/j.tate.2010.06.005

Nketsia, W., Saloviita, T., \& Gyimah, E. K. (2016). Teacher educators' views on inclusive education and teacher preparation in Ghana. International Journal of Whole Schooling, 12(2), 1-18. http://urn.fi/URN:NBN:fi:jyu-201609294225

Ntim, S. (2017). Transforming teaching and learning for quality teacher education in Ghana: Perspectives from selected teacher trainees and stakeholders in teacher education. DOI: 5296/Ije.v9i3.11686.

Pańczyk W., \& Warchoł K. (2008), W kręgu teorii, metodyki i praktyki współczesnego wychowania fizycznego. Uniwersytet Rzeszowski, Wydanie II uzupełnione, Rzeszów.

Pedersen, S. J., Cooley, P. D., \& Hernandez, K. (2014). Are Australian pre-service physical education teachers prepared to teach inclusive physical education? Australian Journal of Teacher Education, 39(8), 11.

\section{http://dx.doi.org/10.14221/ajte.2014v39n8.4}

Quennerstedt, M. (2019). Physical education and the art of teaching: Transformative learning and teaching in physical education and sports pedagogy, Sport, Education and Society, 24:6, 611-623, DOI: $\underline{10.1080 / 13573322.2019 .1574731}$

Salend, S. J., (2010). Evaluating inclusive teacher education programs: A flexible framework. In C. Forlin (Ed), Teacher education for inclusion: Changing paradigms and innovative approaches (pp. 208-214). Abingdon: Routledge.

Sawhney, S. (2015). Unpacking the nature and practices of inclusive education: The case of two schools in Hyderabad, India, International Journal of Inclusive Education, 19(9), 887907, DOI: 10.1080/13603116.2015.1015178. 
Secretaria da Educação Básica (2017). Base Nacional ComumCurricular - Educação é a base. Brasília: Ministério daEducação.

Schleicher, A. (2016). Teaching excellence through professional learning and policy reform: Lessons from around the world. International Summit on the Teaching Profession. Paris: OECD Publishing

Sharma U (2018). Preparing to teach in inclusive classrooms. Oxford University Press USA. Professional Learning and Development.

DOI: 10.1093/acrefore/9780190264093.013.113

Sharma, U., \& Loreman, T. J. (2014). Teacher educator perspectives on systemic barriers to inclusive education. An international conversation. In P. Jones (Ed.), Bringing insider perspectives into inclusive teacher learning. Potentials and challenges for educational professionals (pp. 168-177). London: Routledge

Specht, J., McGhie-Richmond, D., Loreman, T., Mirenda, Bennett, S., Gallagher,T., Young, G., Metsala, J., Aylward, L., Katz, J., Lyons, W., Thompson, S.,\& Cloutier, S. (2015). Teaching in inclusive classrooms: Efficacy and beliefs of Canadian preservice teachers. International Journal of Inclusive Education. DOI: 10.1080/13603116.2015.1059501.

Swanson G. R, \& Cocchiarella M. (2013) Preservice special and general educators' knowledge of inclusion. Teacher Education and Special Education.;36: 204-216

Travers, J., Balfe, T., Butler, C., Day, T., Dupont, M., McDaid, R., O’Donnell, M \& Prunty, A (2010). Addressing the challenges and barriers to inclusion in Irish schools. Report to research and development committee of the department of education and skills. Dublin: DES. 220 European Physical Education Review 21(2) Retrieved from epe.sagepub.com on $3 / 11 / 2018$.

UNICEF. (2012). Global teacher training and inclusion survey: Report for UNICEF rights, Education and Protection Project (REAP).

WHO (2018). Physical activity facts. Retrieved on 10/10/2018 from https//www.who.int/news-room/facts-in-pictures/detail/physical-activity. 